\title{
Comparación entre cesación tabáquica gradual y abrupta
}

\author{
Comparison between gradual and abrupt smoking cessation
}

Lindson-Hawley N, y col. Ann Intern Med. 2016;164:585-592.

\section{Objetivos}

Comparar la cesación tabáquica gradual (CTG) con la abrupta (CTA), ambas utilizando terapia nicotínica de reemplazo (TNR) previas a la fecha para dejar (día D).

\section{Diseño, lugar y pacientes}

Estudio aleatorizado, controlado, de no inferioridad (no ciego) que incluyó 697 fumadores de al menos 15 cigarrillos/día o $12,5 \mathrm{~g}$ de tabaco/día o con monóxido de carbono exhalado (COexh) de al menos $15 \mathrm{ppm}$. Reclutados en la atención primaria en Inglaterra entre 2009 y 2011. Enfermeras entrenadas implementaron la consejería durante ocho visitas. Ambas ramas recibieron parches de $21 \mathrm{mg} /$ día desde dos semanas previas al día D. El grupo CTG sumaba otra TNR (comprimidos, chicles, sublinguales, spray nasal, inhalador) con la consigna de reducir al $75 \%$ lo fumado. Todos continuaron con parches más otras TNR desde el día $\mathrm{D}$.

\section{Evaluación de factores pronósticos}

Estimación de cesación según criterios de Russell a las cuatro semanas (objetivo primario) y 26 semanas (objetivo secundario)1. Escalas de síntomas de abstinencia.

\section{Medición de resultados principales}

Cálculo del riesgo relativo (RR) para margen de no inferioridad de 0,81 o reducción del $19 \%$. Análisis por intención de tratar.

\section{Resultados Principales}

A las cuatro semanas fue más efectiva la CTA, con un RR ajustado de 0,80 (IC95\% 0,66 a 0,93). Ambos grupos tuvieron similar cumplimiento de visitas y de adherencia a TNR. El $68 \%$ de la CTG cumplió con la meta de reducción. La TNR oral complementaria fue más elegida aunque usada por debajo de lo prescripto. No hubo diferencias en los síntomas de abstinencia $(p=0,29)$.

Tabla 1. Tasas de cesación y riesgo relativo de cesación tabáquica gradual comparada con cesación tabáquica abrupta.

\begin{tabular}{|c|c|c|c|c|}
\hline Resultado & CTG $n=362(\%)$ & CTA $n=355(\%)$ & Diferencia absoluta (IC95\%) & RR (IC95\%) \\
\hline \multicolumn{5}{|l|}{ Cesación prolongada por COexh } \\
\hline $\begin{array}{l}\text { a las } 4 \text { semanas } \\
\text { a las } 8 \text { semanas } \\
\text { a las } 26 \text { semanas ( } 6 \text { meses) }\end{array}$ & $\begin{array}{c}134(39,2) \\
100(29,2) \\
53(15,5)\end{array}$ & $\begin{array}{l}174(49,0) \\
130(36,6) \\
78(22,0)\end{array}$ & $\begin{array}{l}9,8(2,5 \text { a } 17,1) \\
7,4(0,4 \text { a } 14,3) \\
6,5(0,7 \text { a } 12,2)\end{array}$ & $\begin{array}{l}0,80(0,66 \text { a } 0,93) \\
0,80(0,63 \text { a } 0,91) \\
0,71(0,46 \text { a } 0,91)\end{array}$ \\
\hline $\begin{array}{l}\text { Cesación puntual de } 7 \text { días (no haber } \\
\text { fumado la semana previa a la entrevista) }\end{array}$ & & & & $0,83(0,72$ a 0,98$)$ \\
\hline $\begin{array}{l}\text { a las } 4 \text { semanas } \\
\text { a las } 8 \text { semanas } \\
\text { a las } 26 \text { semanas ( } 6 \text { meses) }\end{array}$ & $\begin{array}{l}146(42,7) \\
106(31,0) \\
63(18,4)\end{array}$ & $\begin{array}{l}191(53,8) \\
136(38,3) \\
94(26,5)\end{array}$ & $\begin{array}{l}9,1(1,8 \text { a } 16,5) \\
7,3(0,3 \text { a } 14,3) \\
8,1(1,9 \text { a } 14,2)\end{array}$ & $\begin{array}{l}0,81(0,68 \text { a } 1,04) \\
0,70(0,51 \text { a } 0,97)\end{array}$ \\
\hline Cesación autoreportada & & & & $0,87(0,77$ a 0,97$)$ \\
\hline $24 \mathrm{hs}$ & $210(61,4)$ & $252(71,0)$ & $9,6(2,6$ a 16,5$)$ & \\
\hline
\end{tabular}

COexh: monóxido de carbono exhalado.

Dejar de fumar abruptamente desde una fecha concreta, resulta Fuente de financiación: British Heart Foundation. más eficaz que realizar una reducción forzada previa.

\section{Comentario}

El estándar nacional para TNR es su uso desde una fecha a corto plazo en quienes están listos para dejar ${ }^{2}$. Una breve preparación comprende tareas prácticas (ej. planilla de consumo diario de cigarrillos, manual de autoayuda, fumar afuera) lo que puede generar una natural disminución no forzada. Por otro lado, la TNR es efectiva incluso en quienes prefieren no dejar abruptamente, pero este "reducir para dejar" aumentaría costos con pobre beneficio ${ }^{3}$. Una revisión sistemática no mostró superioridad entre dejar abruptamente o reducir previamente (RR 0,94 IC95\% $0,79$ a 1,13$)^{4}$. Sin embargo aquí la reducción forzada durante dos semanas fue menos eficaz respecto a dejar abruptamente, incluso siendo la preferencia pre-aleatorización de los fumadores el querer hacerlo gradualmente $(50,9 \%)$.

\section{Conclusiones del comentador}

Más allá de que el fumador tienda a elegir reducir antes que concretar una fecha, es efectivo proponer un Día D. Estrategias de reducción gradual como TNR mientras se fuma o similares no tienen mayor eficacia para dejar ${ }^{5}$.

Brunilda Casetta [ Instituto Universitario del Centro de Educación Médica e Investigaciones Clínicas (CEMIC). bcasetta@ cemic.edu.ar ]

Casetta B. Comparación entre cesación tabáquica gradual y abrupta .Evid Act Pract Ambul. 2017;20(1):8. Comentado de: Lindson-Hawley N y col. Gradual Versus Abrupt Smoking Cessation. A Randomized, Controlled Noninferiority Trial. Ann Intern Med. 2016;164:585-592. PMID: 26975007.

\section{Referencias}

1. West R, y col. Outcome criteria in smoking cessation trials: proposal for a common standard. Addiction 2005;100:299-303.

2. Ministerio de Salud de la Nación. Guía de Práctica Clínica Nacional de Tratamiento de la Adicción al Tabaco. Buenos Aires: Estrategia Nacional de Prevención y Control de Enfermedades no Transmisibles. ; 2011.

3 . Wang D, y col. 'Cut down to quit' with nicotine replacement therapies in smoking cessation: a systematic review of effectiveness and economic analysis. Health Technol Assess 3. Wang D, y col. "Cut down

2008;12:iii-iv, ix-xi, 1-135.

5. Godtfredsen NS, y col. Smoking Reduction, Smoking Cessation, and Mortality: A 16-year Follow-up of 19,732 Men and Women from the Copenhagen Centre for Prospective Population Studies. American Journal of Epidemiology 2002;156:994-1001. 